Volume 3 • Nomor 1 • Oktober 2019

Pege $($ Hal. $): 88-98$

(C) Universitas Pamulang

JL.Surya Kencana No.1 Pamulang, Tangerang Selatan - Banten

Telp. (021) 7412566, Fax (021) 7412491

website. :

Email : jurnalmarketing.unpam@gmail.com

\title{
Pengaruh Daya Tarik Iklan Dan Penempatan Produk Terhadap Kesadaran Merek Grab di Acara Indonesian Idol 2018
}

\author{
Ade Onny Siagian \\ Universitas Bina Sarana Informatika, : adegiant78@gmail.com
}

\begin{abstract}
Abstrak. Penelitian ini bertujuan untuk mengetahui apakah penempatan produk berpengaruh positif terhadap kesadaran merek, apakah penempatan produk berpengaruh positif terhadap niat beli dan apakah kesadaran merek berpengaruh positif terhadap nniat beli di Acara Indonesian Idol 2018. Penelitian ini dilakukan dengan metode penelitian kuantitatif melalui kuesioner online. Penelitian ini menggunakan metode purposive sampling dan ditujukan pada responden yang pernah menonton Indonesian Idol 2018. Penelitian ini terdiri dari 154 responden. Data dianalisis menggunakan pemodelan persamaan struktural. Hasil penelitian menunjukkan bahwa ada dua hipotesis yang didukung dan satu hipotesis yang tidak didukung. Penelitian ini menyimpulkan bahwa ada pengaruh positif dari penempatan produk dan kesadaran merek, tidak ada pengaruh positif dari penempatan dan niat beli produk, dan ada pengaruh positif dari kesadaran merek dan niat beli.
\end{abstract}

\section{Keywords: Penempatan Produk; Kesadaran Merek; Niat Membeli}

Abstract. This research was conducted to determine whether product pacement had a positive effect on brand awareness, product placement had positive effect on purchasing desire and brand awareness had postitve effect on purchasing desire of grab merk at Indonesian Idol audience 2018 . This research was conducted with quantitative research methods through an online questionnaire. This study applied a purposive sampling method and was aimed at respondents who had watched Indonesian Idol 2018. The study consisted of 154 respondents. Data were analyzed using structural equation modeling. The results show that there are two supported hypotheses and one hypothesis that is not supported. This study concludes that there is a positive influence of product placement and brand awareness, there is no positive influence of product placement and purchase intention, and there is a positive influence of brand awareness and purchase intention.

Key words: Product Placement: Brand Awareness; Purchasing Desire

\section{A. PENDAHULUAN}

Perkembangan teknologi dirasakan terus semakin meningkat dari masa ke masa. Banyak orang yang mencari informasi dari internet maupun mendapatkan informasi melalui televisi, radio dan majalah. Oleh karena itu, pemasar dapat menggunakan kesempatan ini untuk mempromosikan dan mengkomunikasikan produknya. Iklan menjadi pilihan utama dalam mengkomunikasikan produk yang ditawarkan oleh perusahaan.

Banyak perusahaan yang memanfaatkan iklan di majalah, televisi ataupun koran sebagai media untuk menyampaikan produknya. Peranan iklan sangat besar pengaruhnya dalam menjaga eksistensi dan dalam memperkuat dari segi keuntungan bagi media itu sendiri. Dengan jumlah kepemirsaan yang tinggi hal itu dimanfaatkan oleh pengiklan untuk menayangkan produknya. Menurut survey yang dilakukan oleh Nielsen Indonesia, perusahaan yang memberikan pemahaman terhadap apa yang konsumen 
tonton dan beli, jumlah belanja iklan meningkat $5 \%$ sebesar Rp 75,1 triliun pada tahun 2018 , dan $82 \%$ merupakan belanja iklan dari media televise (widyastuti., 2018). Sedangkan belanja iklan distasiun televisi didominasi oleh RCTI dengan Rp. 14,76 triliun. Gambar 1. Menunjukkan tingkat belanja iklan di stasiun televisi pada tahun 2018.

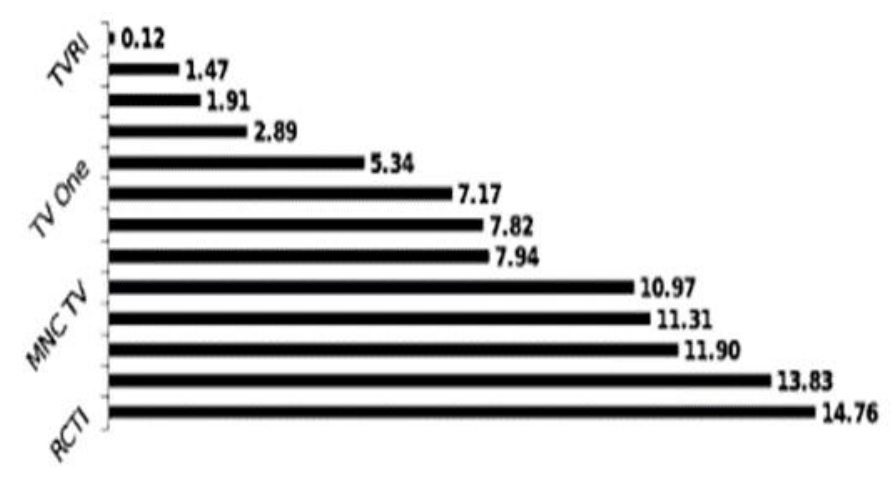

\section{Gambar 1. Grafik Pendapatan Media tahun 2018}

Tujuan utama dalam melakukan komunikasi pemasaran adalah meningkatkan kesadaran merek. Tingkat kesadaran akan merek yang tinggi akan memengaruhi niat membeli seseorang. Untuk menciptakan komunikasi yang baik, iklan dapat digunakan untuk penempatan produk. Penempatan produk merupakan salah satu industri iklan yang paling berkembang (Matthes \& Naderer, 2016).Penempatan produk akan membuat perhatian penonton secara tidak langsung terpusatkan pada mereka tau produk yang diletakkan pada acara televisi maupun film, dan perusahaan yang menggunakan penempatan produk dapat menghindari zipping dan zapping (Purnomo, 2015). PQ Media menyatakan penempatan produk di Amerika berkembang sebesar 12,8\% di tahun 2014 yaitu sebesar 6 miliar, dan akan mencapai 11 miliar dollar pada tahun 2019 (Muzellec, 2016). Sedangkan di Indonesia, berdasarkan Riset Nielson Indonesia, penayangan iklan dalam program televisi semakin menanjak. Kemunculan iklan dalam program televisi mengisi $22 \%$ dari slot iklan. Penempatan produk menjadi bentuk paling mendominasi dengan $29 \%$ dari jumlah tayangan. Ketika jeda iklan, rating siaran televisi umumnya cenderung menurun karena penonton gemar mengganti saluran (Bernie, 2017).

Rumusan Masalah: 1.Apakah terdapat pengaruh positif antara penempatan produk dan kesadaran merek Grab pada acara Indonesian Idol 2018? 2. Apakah terdapat pengaruh positif antara penempatan produk dan niat membeli Merek Grab pada acara Indonesian Idol 2018? 3.Apakah terdapat pengaruh positif antara kesadaran merek dan niat membeli merek Grab pada acara Indonesian Idol 2018

Tujuan Penelitian: 1. Untuk mengetahui pengaruh penempatan produk terhadap kesadaran merek Grab pada acara Indonesian Idol 2018. 2. Untuk mengetahui pengaruh penempatan produk terhadap niat membeli merek Grab pada acara Indonesian Idol 2018. 3. Untuk mengetahui pengaruh kesadaran merek terhadap niat membeli merek Grab pada acara Indonesian Idol 2018

\section{B. KAJIAN LITERATUR}

Penempatan Produk 
Penempatan produk adalah salah satu jenis iklan yang dapat digunakan oleh pemasar untuk mengkomunikasikan dan mempromosikan produknya. Tujuan dari penempatan produk adalah menciptakan asosiasi, menunjukkan cara penggunaan produk, dan juga meningkatkan kesadaran merek(Ouwersloot \& Duncan, 2008). Merek harus digabungkan dengan acara, situasi penggunaan, karakter, dan plot. Acara yang digunakan akan berperan penting terhadap keefektifan penempatan produk(Gibson, Redker, \& Zimmerman, 2013).

Kesadaran Merek

Aaker dalam (Yang, 2009) menyatakan kesadaran merek (Brand Awareness) adalah kemampuan konsumen dalam mengenali dan mengingat suatu merek dalam situasi yang berbeda. Rossiter dan Percy dalam (Macdonald, 2003) menyatakan bahwa kesadaran merek (brand awareness) menjadi aspek yang penting dalam terjadinya proses komunikasi dikarenakan mendahului semua langkah langkah lain dalam proses komunikasi.

Niat Beli

Niat membeli adalah kegiatan yang dilakukan ketika individu memutuskan untuk membeli merektertentu setelah beberapa pertimbangan(Ajzen, 1991; Koenig-Lewis \& Palmer, 2014). Niat beli cenderung terbentuk karena hasil dari tahap evaluasi.Seseorang memiliki niat untuk membeli produk yang dianggap sesuai dengan kebutuhannya(Das, 2014; Vijaranakorn \& Shannon, 2017).Dalam melakukan pembelian, niat sangat berkaitan erat dengan motif pembelian.Motif pembelian setiap konsumen berbeda tergantung keadaan(Coelho, Meneses, \& Moreira, 2013; Defranc et al.,2008; Rudyanto, 2018).

\section{METODOLOGI PENELITIAN}

Unit analisis dalam riset ini adalah individu. Sedangkan obyek penelitian adalah Grab pada acara Indonesia Idol 2018. Grab dipilih menjadi obyek penelitian karena Grab merupakan sponsor utama dalam acara pencarian bakat Indonesian Idol 2018 seperti yang dipaparkan oleh Tantan Sumaartana sebagai sales dan marketing director dari RCTI (Darandono, 2017). Teknik penarikan sampel menggunakan metode sampling non-probabilitas dengan tipe purposive sampling (Sekaran dan Bougie, 2016). Responden dalam penelitian ini adalah yang pernah menonton Indonesian Idol 2018 setidaknya sekali. Dalam penelitian ini, sampel penelitian berjumlah 154 responden. Data dianalisis dengan menggunakan Partial Least Square-Structural Equation Modeling(PLS-SEM). Ada 2 bagian dalam PLS-SEM. Pertama, model pengukuran merupakan pengukuran apakah variable yang diobservasi dapat menunjukkan variabel laten yang diukur. Kedua, model struktural dilakukan untuk mengukur kekuatan dari variabel laten (Ghozali dan Latan, 2015). Dalam melakukan pengujian PLS-SEM, peneliti menggunakan software SPSS untuk melakukan statistik deskripsi dan reliabilitas, kemudian software Smart PLS 3.0 untuk menguji validitas dan uji hipotesis

\section{HASIL DAN PEMBAHASAN}

Dari kuesioner tersebut dapat digambarkan profil responden sebagai berikut dalam Tabel 2 .

Tabel 2. Profil Responden 
ISSN NO. (PRINI) 2598-0823, (ONLINE) 2598-2893

\begin{tabular}{lccc}
\hline \multicolumn{1}{c}{ Variabel Demografis } & kategori & Jumlah & Presentasi (\%) \\
\hline Jenis Kelamin & Pria & 39 & $25,32 \%$ \\
& Wanita & 115 & $74,6 \%$ \\
Usia & $<20$ & 29 & $18,83 \%$ \\
& $20-25$ & 122 & $79,22 \%$ \\
& $26-30$ & 2 & $1,2 \%$ \\
& $>30$ & 1 & $0,6 \%$ \\
\hline Frekuensi menyaksikan & $<3$ kali & 48 & $31,16 \%$ \\
Indonesia Idol & $3-5$ kali & 36 & $23,37 \%$ \\
& $<5$ kali & 70 & $45,45 \%$ \\
\hline
\end{tabular}

Sumber: hasil olah data

Dari 154 responden yang telah mengisi kuisioner, responden didominasi oleh 115 responden wanita dengan presentasi $74,67 \%$, sedangkan responden pria terdiri dari 39 dengan presentasi $25,32 \%$. Kemudian, untuk kategori usia, terdapat 29 responden yang berusia dibawah 20 tahun, 122 responden yang berusia 21-25 tahun, 2 responden yang berusia 26-30 tahun, dan 1 responden yang berusia diatas 30 tahun. Responden yang berusia 20-25 tahun memiliki jumlah terbanyak dalam kategori usia dengan persentasi sebesar $79 \%$. Terakhir, mayoritas responden pernah menonton acara Indonesia idol lebih dari 5 kali dengan jumlah 70 responden. Presentasi dari responden yang menonton Indonesia idol lebih dari lima kali adalah 45,45\%.

Tabel 3. Hasil Uji Reliabilitas

\begin{tabular}{lcc}
\hline \multicolumn{1}{c}{ Variabel } & $\begin{array}{c}\text { Cronbach's } \\
\text { alpha } \\
\text { coefficient }\end{array}$ & $\begin{array}{c}\text { Corrected } \\
\text { item total } \\
\text { correlation }\end{array}$ \\
\hline $\begin{array}{l}\text { Penempatan produk } \\
\text { 1. Logo merek Grab terlihat jelas pada } \\
\text { acara Indonesia Idol 2018 }\end{array}$ & 0,74 \\
2. Nama Merek Grab terlihat jelas & 0,87 & 0,81 \\
pada acara Indonesia Idol 2018 & & 0,77 \\
3. Aplikasi Grab diperlihatkan secara & & \\
4. Cara penggunaan aplikasi Grab & & 0,61 \\
\hline $\begin{array}{l}\text { Indunjukkan secara jelas di acara } \\
\text { Indonesia Idol 2018. }\end{array}$ & & \\
\hline
\end{tabular}


Kesadaran merek.

1. Saya menyadari adanya merek

Grab pada acara Indonesia Idol 2018.

2. Saya mengenal merek Grab 0,71 sebagai merek dari taxi online.

3. Merek Grab memiliki ciri khas.

4. Saat produk taxi online disebutkan, Grab menjadi merek yang pertama kali saya pikirkan.

Nilai Membeli

1. Saya ingin mencoba produk Grab setelah saya melihat Indonesian Idol 2018.

2. Saya akan mempertimbangkan untuk menggunakan Grab setelah menonton Indonesian Idol 2018.

3. Saya bersedia untuk menggunakan

Grab setelah melihat Indonesian Idol 2018.

4. Kemungkinan tinggi bagi saya untuk menggunakan Grab.

5. Saya akan memilih Grab saat menggunakan taxi online.

\section{Sumber: Hasil olah data}

Syarat yang digunakan untuk uji reliabilitas adalah batas Cronbach's coefficient alpha lebih dari 0,7 dan batas untuk corrected item total correlation adalah 0,4. Tabel 3 diatas menunjukkan bahwa hasil pengujian reliabilitas memenuhi syarat.

Tabel 4. Hasil Exploratory Factor Analysis

\begin{tabular}{cc}
\hline Kesadaran merek & Niat membeli \\
& $\begin{array}{c}\text { Penempatan } \\
\text { produk }\end{array}$
\end{tabular}



B1
0,759
B2
0,835
B3
0,701
B4
0,650

P1

0,846

P2

0,835

P3

0,891

P4

0,801

P5

0,735

PP1

0,873

PP2

0,907

PP3

0,872

PP4

0,772

Sumber : Hasil olah data

Berdasarkan informasi dari table 4 diatas, dapat dilihat bahwa semua nilai loading berada diatas 0,6 . Ini menunjukkan bahwa semua nilai validitas yang ada telah memenuhi syarat. Dengan demikian, pengujian hipotesis dapat dilakukan Tabel 5.

Tabel 5. Hasil Uji Hipotesis

\begin{tabular}{lcc}
\hline \multicolumn{1}{c}{ Hipotesis } & P.Value & Kesimpulan \\
\hline $\begin{array}{l}\text { H1: penempatan produk berpengaruh positif } \\
\text { terhadap kesadaran merek. }\end{array}$ & 0,00 & Didukung \\
H2: Penempatan produk berpengaruh positif & 0,33 & Tidak didukung \\
terhadap niat membeli. & & didukung \\
H3: Kesadaran merek berpengaruh positif \\
terhadap niat membeli.
\end{tabular}

Sumber: Hasil olah data

Hipotesis yang pertama menyatakan adanya pengaruh positif antara penempatan produk dan kesadaran merek. Hasil analisis menunjukan bahwa hipotesis didukung. Sebagaimana bahwa tujuan dari penempatan produk adalah menciptakan asosiasi, menunjukkan cara Jurnal Pemasaran Kompetitif, Vol. 03, No. 1 / Oktober 2019 
penggunaan produk, dan juga meningkatkan kesadaran merek (Ouwersloot dan Duncan, 2008). Hasil penelitian ini sesuai dengan hasil penelitian sebelumnya yang dilakukan oleh (Kristanto dan Brahmana, 2016) dimana terdapat hubungan positif antara penempatan produk dan kesadaran merek.

Hipotesis yang kedua menyatakan adanya hubungan positif antara penempatan produk dan niat membeli. Hipotesis kedua dalam penelitian ini tidak didukung. Dengan tidak didukungnya hipotesis kedua, menunjukkan bahwa tidak ada hubungan positif antara penempatan dan niat membeli. Terdapat beberapa alasan mengapa hipotesis ini tidak didukung. Pertama, responden pada penelitian ini didominasi oleh wanita dengan persentasi $75 \%$ wanita cenderung menggunakan otak kanan dalam mengambil keputusan (Pratiwi, 2017). Hal ini membuat wanita melihat suatu masalah dari berbagai sudut pandang dan lebih menggunakan perasaan yang kemudian menyebabkan pengambilan keputusan menjadi lama untuk dilakukan. Oleh karena itu, kemungkinan penempatan produk yang disandari oleh responden tidak langsung dapat menimbulkan niat membeli, karena responden mempertimbangkan faktor lain sebelum niat membeli suatu produk tercipta. Kedua, berdasarkan hasil dari statistik yang dilakukan pada penelitian ini rata-rata responden menjawab pertanyaan untuk indicator pertama hingga keempat dengan jawaban netral indicator pertama menyatakan "saya ingin mencoba Grab setelah saya menonton acara Indonesian Idol 2018". Rata-rata dari indicator tersebut adalah 3,26 dan sabanyakn 61 responden yang menjawab pertanyaan tersebut dengan jawaban netral. Hal tersebut mengakibatkan hubungan antar penempatan produk dan niat membeli tidak didukung. Ketiga, penelitian yang dilakukan oleh (Zulganef dan Ramadhika, 2014) juga menunjukkan bahwa tidak ada hubungan positif antara penempatan produk dan niat membeli. Penonton juga dapat mengganti saluran telivisi, sehingga mengurangi keefektifan yang diberikan penempatan produk (Purnomo, 2015). Hal tersebut dapat menjadi alasan mengapa hipotesis hubungan positif antara penempatan produk dan niat membeli tidak didukung.

Hipotesis yang ketiga menyatakan adanya hubungan positif antara kesadaran merek dan niat membeli. Hasil analisis mendukung hipotesis ini. Hipotesis ini dikembangkan dari landasan teori bahwa seorang pemasar harus dapat membangun loyalitas merek, dengan terus meningkatkan kesadaran merek agar konsumen merasa lebih tertarik pada suatu merek dibandingkan merek lain sehingga menimbulkan pembelian berulang (Belch dan Belch, 2015). Adanya hubungan positif antara kesadaran merek dan niat membeli menandakan bahwa apabila masyarakat Indonesua semakin menyadari akan kehadiran merek, maka niat membeli pada suatu produk akan semakin meningkat. Peneliti lain juga memperlihatkan bahwa kesadaran merek akan menimbulkan pembelian berulang (Belch dan Belch, 2015). Lebih lanjut, penelitian yang dilakukan oleh (Dharamdasani dan Sharma,2017) serta (Kristanto dan Brahmana, 2016), menyatakan bahwa terdapat hubungan positif antara kesadaran merek dan niat membeli. Menurut (Dharamdasani dan Sharma,2017), konsumen yang menyadari dan mengenal merek akan mempermudah konsumen dalam keputusan pembelian. Berdasarkan hasil tersebut, dapat disimpulkan bahwa semakin tinggi konsumen menyadari adanya merek Grab. Maka semakin tinggi niat konsumen untuk membeli atau menggunakan Grab tersebut.

\section{E. KESIMPULAN}

Hasil analisis memperlihatkan bahwa ada hubungan positif antara penempatan produk dan kesadaran merek. Lebih lanjut, hasil anilisis memperlihatkan hubungan positif antara 
kesadaran merek dengan niat beli. Dengan demikian, dapat disimpulkan bahwa kesadaran merek adalah variable mediasi antara hubungan penempatan produk dan niat untuk membeli.

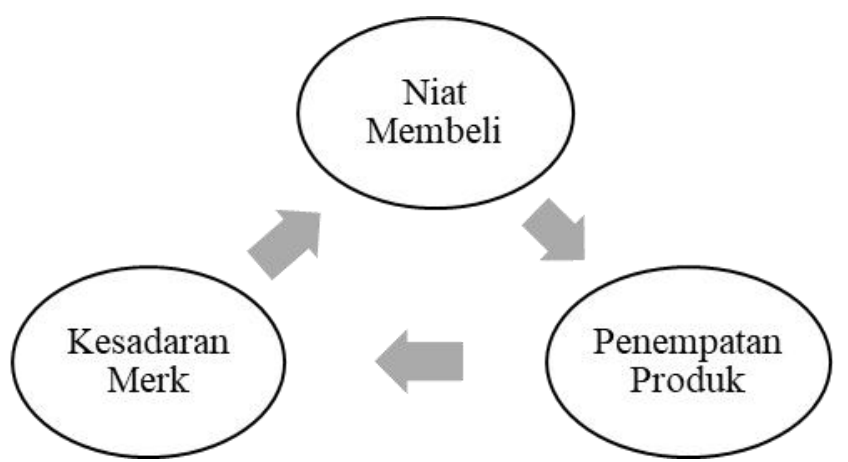

Gambar 2. Kerangka Konseptual

\section{IMPLIKASI}

Berdasarkan hasil penelitian ini, dapat ditarik kontribusi teoritis, yaitu adanya teori baru yang berbeda dengan penelitian sebelumnya. Hasil penelitian ini menunjukkan bahwa terdapat pengaruh positif penempatan produk terhadap kesadaran merek. Selain itu, terdapat pengaruh positif kesadaran merek terhadap niat membeli. Akan tetapi dalam penelitian ini tidak terdapat pengaruh positif penempatan produk terhadap niat membeli. Implikasi manajerial yang dapat diberikan untuk acara Indonesian Idol 2018 adalah untuk lebih meningkatkan beberapa hal Tabel 6. penempatan produk berpengaruh terhadap kesadaran merek. Untuk meningkatkan kesadaran merek dari Grab, Grab harus menempatkan logo dan nama merek secara jelas pada media seperti acara televisi supaya dapat dilihat dan disadari oleh penonton. Cara penggunaan dari aplikasi Grab juga dapat ditunjukkan secara jelas pada acara televisi agar penonton dapat memahami cara menggunakan aplikasi Grab tersebut. Cara menempatkan produk yang menonjol dan tidak menggangu juga dapat meningkatkan kesadaran merek dari Grab.

Grab juga dapat meningkatkan komunikasi pemasaran terhadap merek dan penggunaan aplikasinya untuk meningkatkan kesadaran merek di benak konsumen. Grab dapat memanfaatkan iklan, atau penempatan produk pada film terkenal untuk meningkatkan kesadaran merek konsumen. Grab dapat menciptakan merek yang unik dan mudah dikenali serta memiliki ciri khas dibandingkan saingannya agar konsumen dapat mengenal merek Grab setelah melihat merek dan logonya, dan juga dapat mengingat Grab pertama kali saat taksi online disebutkan. Grab harus meningkatkan komunikasi dan promosi produk yang ditawarkan, juga meningkatkan kualitas dan pelayanan dari Grab, supaya konsumen dapat tertarik untuk menggunakan Grab sebagai taksi online. Grab harus memperhatikan kualitas dan pelayanan yang diberikan, agar konsumen percaya dan menciptakan niat untuk menggunakan Grab sebagai alat transportasi sehari-hari. 
Tabel 6. Implikasi Manajerial

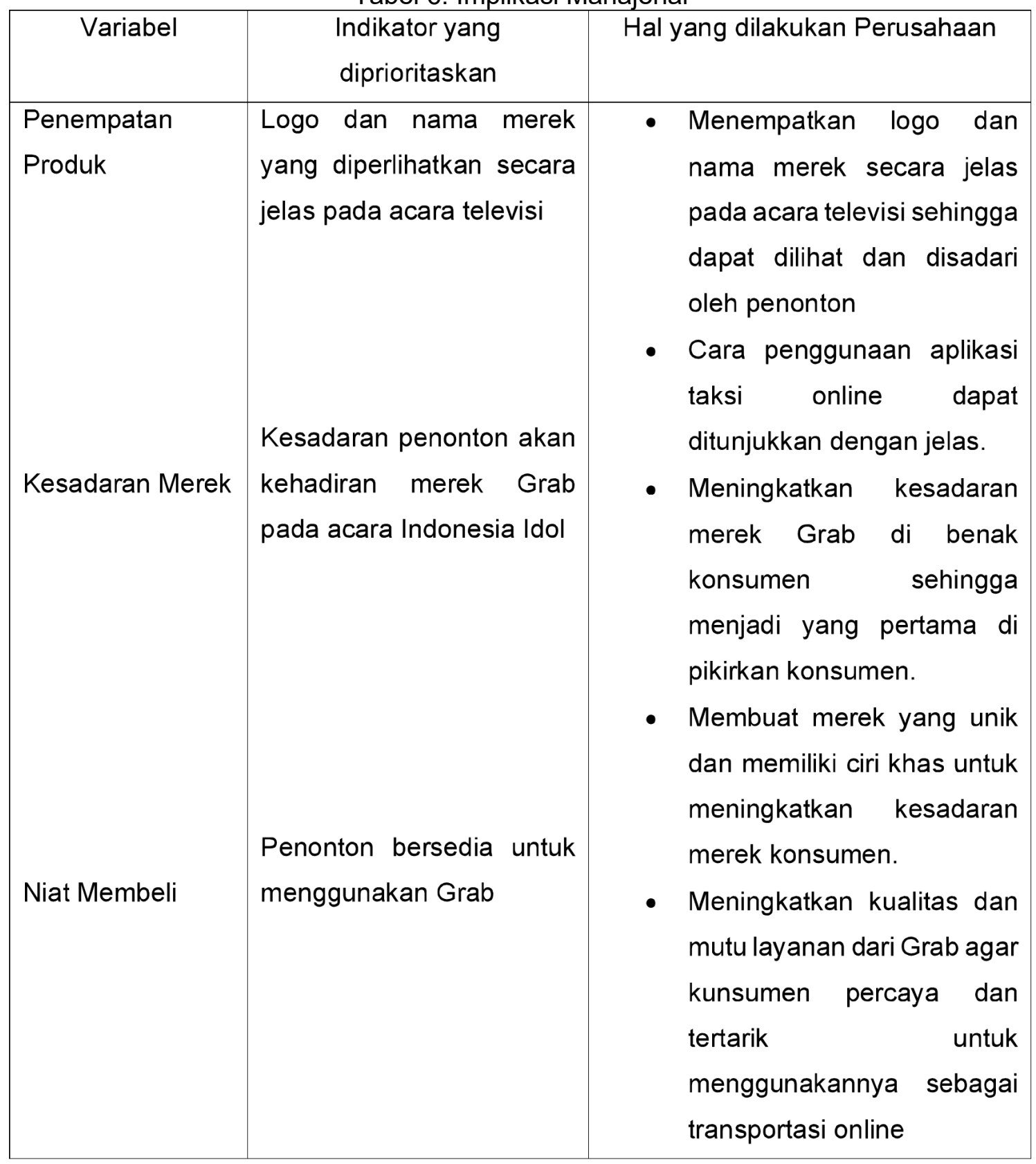

Saran: berdasarkan hasil penelitian dan keterbatasan dalam penelitian ini, maka terdapat beberapa saran untuk penelitian selanjutnya. Yang pertama terdapat pada obyek penelitian. Ini adalah penempatan produk Grab pada acara Indonesia Idol 2018. Penelitian selanjutnya dapat menggunakan penempatan produk lain, atau menggunakan media lain seperti film, sinetron, dan acara televisi lainnya.

Saran yang kedua adalah dalam teknik pengambilan sampel. Dalam penelitian ini, teknik pengambilan sampel yang digunakan adalah sampling non-probabilitas. Sampling nonprobabilitas menyebabkan adanya kemungkinan populasi yang tidak memiliki probabilitas yang sama untuk menjadi responden. Penelitian selanjutnya dapat menggunakan teknik 
pengambilan sampel sampling probabilitas sehingga semua populasi mendapatkan probabilitas yang sama untuk menjadi responden. Dengan menggunakan sampling probabilitas, penelitian yang dilakukan dapat digeneralisasi.

\section{DAFTAR PUSTAKA}

Belch, G., \& Belch, M. (2015). Advertising and promotion: An integrated marketing communications perspective. (10th ed.). Singapore: McGraw-Hill Education.

Bernie, M. (2017). Riset Nielsen: Iklan yang "Menyusup" di program TV makin banyak. Retrieved September 11, 2018, from https://tirto.id/riset-nielsen-iklan-yangmenyusupdi-program-tv-makin-banyak-cAvd

Bian, Q., \& Forsythe, S. (2012). Purchase intention for luxury brands: A cross cultural comparison. Journal of Business Research, 65(10), 1443-1451. Retrieved from https://doi.org/10.1016/j.jbusres.2011.10.010

Buil, I., de Chernatony, L., \& Martínez, E. (2013). Examining the role of advertising and sales promotions in brand equity creation. Journal of Business Research, 66(1), 115-122. https://doi.org/10.1016/j.jbusres.2011.07.030 Chen

Darandono. (2017). RCTI Gandeng Grab Gelar Indonesia Idol Sesson 9. Retrieved September 11, 2018, from https://swa.co.id/swa/trends/marketing/rcti-gandenggrab-gelarindonesia-idol-sesson-9

Dharamdasani, D., \& Sharma, M. (2017). Impact of brand related attributes on consumer's purchase intention towards private label apparels brands: A study about the consumers of Ahmedabad. International Journal of Engineering and Management Research, 7(1), 297-303. Retrieved from http://www.ijemr.net/DOC/ImpactofBrandRelatedAttributesonConsumersPurchasel nten tionTowardsPrivateLabelApparelsBrandsAStudyAbouttheConsumersofAhmedabad. PDF

Ghozali, I., \& Latan, H. (2015). Partial least square: Konsep, teknik dan aplikasi menggunakan program Smartpls 3.0 untuk penelitian empiris. Semarang: Badan Penerbit UNDIP.

Kristanto, H., \& Brahmana, R. K. M. R. (2016). Pengaruh product placement pada film Indonesia terhadap brand awareness dan purchase intention masyarakat Surabaya. Jurnal Manajemen Pemasaran, 10(1), 20-26. https://doi.org/10.9744/pemasaran.10.1.20-26

Lehu, J.-M., \& Bressoud, É. (2009). Recall of brand placement in movies: Interactions between prominence and plot connection in real conditions of exposure. Recherche et Applications En Marketing, 24(1), 7-26. https://doi.org/10.1177/205157070902400102

Matthes, J., \& Naderer, B. (2016). Product placement disclosures: Exploring the moderating effect of placement frequency on brand responses via persuasion knowledge. International Journal of Advertising, 35(2), 185-199. https://doi.org/10.1080/02650487.2015.1071947

Muzellec, L. (2016). James Bond, Dunder Mifflin, and the future of product placement. Retrieved October 10, 2018, from https://hbr.org/2016/06/james-bond-dundermifflinand-the-future-of-product-placement

Ouwersloot, H., \& Duncan, T. (2008). Integrated marketing communications (European). London: McGraw-Hill Education.

Pratiwi, R. (2017). Perbedaan cara berpikir perempuan dan laki-laki. Retrieved October 20, 2018, from https://hellosehat.com/hidup-sehat/fakta-unik/perbedaan-caraberpikirperempuan-dan-laki-laki/ 
Purnomo, Z. V. (2015). Product placement: Film, program televisi, video games atau musik? Jurnal Studi Manajemen, 9(1), 100-114. Retrieved from http://journal.trunojoyo.ac.id/kompetensi/article/view/1417

Sekaran, U., \& Bougie, R. (2016). Research methods for business: A skill-building approach (7th ed.). New Jersey: John Wiley \& Sons.

Widyastuti, R. A. Y. (2018). Nielsen: Belanja iklan nasional semester I tembus Rp 75,1 T. Retrieved October 9, 2018, from https://bisnis.tempo.co/read/1116495/nielsenbelanjaiklan-nasional-semester-i-tembus-rp-751-t/full\&view=ok

Zulganef, \& Ramadhika, A. (2014). Analisis efek product placement dan brand awareness. Economics \& Busine

ss Research Festival, 3, 372-385. 